\title{
TRACHEAL EXTENSION IN RESPIRATION
}

\author{
BY \\ R. S. HARRIS \\ From the Department of Anatomy, University of Bristol*
}

(RECEIVED FOR PUBLICATION JANUARY 19, 1959)

It has long been known that the lower end and bifurcation of the trachea are displaced downwards during inspiration. Macklin (1925) described a vertical respiratory displacement of $21 \mathrm{~mm}$. in a healthy young adult female. Brückner (1952), in a radiological study, demonstrated an inspiratory descent of the carina of about one thoracic vertebral body in young adults of 19 to 25 years of age. Holden and Ardran (1957), in a meticulous examination of bronchograms from subjects aged 12 to 65 years, concluded that "in deep inspiration the trachea increased in length up to one fifth and in diameter by about one tenth." In a personal observation, on inspiration the carina descended $30 \mathrm{~mm}$. in a young adult male with a full inspiratory movement. Thus, in young adults, the carina descends by about 1 in. $(2.5 \mathrm{~cm}$.) with deep inspiration, i.e., about $20 \%$ of the unextended length of the trachea.

There are no references in the literature to similar observations in infants and young children in whom the technical difficulty of securing a full inspiratory and expiratory movement for radiographic investigation is obvious. Also, most observers have examined only the movement of the carina and have not considered changes in the whole length of the trachea.

Keith (1909) drew attention to the fact that certain parts of the lung are expanded more readily than others. The bases and sterno-costal surfaces related to the more mobile parts of the thoracic wall expand more readily than the apices, mediastinal surfaces, and posterior margins, related to less mobile parts. These areas he described as areas of direct or of indirect expansion.

The thoracic wall does not move uniformly during inspiration; the parts which move most are the diaphragmatic and sterno-costal surfaces. Thus the lung tends to expand in a downward and forward direction. Now the lung root must obviously descend to facilitate this movement. In

\footnotetext{
*Present address: Department of Child Health, Bristol Royal Hospital for Sick Children.
}

addition it moves anteriorly: for example, we have found that in a healthy young adult male there was an anterior respiratory displacement of the tracheal bifurcation of 0.75 in. $(19 \mathrm{~mm}$.). What is the significance of the respiratory descent of the tracheal bifurcation? Does it facilitate the expansion of the more apical parts of the lung allowing them to expand indirectly, i.e., after more mobile parts of the lung have moved inferiorly and anteriorly?

Now respiratory movements in infancy are different from those in older children and adults. A conspicuous anatomical difference exists between the ribs of these groups. The ribs of an infant are much more nearly horizontal than those of an adult (Mehnert, 1901), and it is stated by Engel (1947) that the adult obliquity is not assumed until about the seventh year. Observation of the abdomen of an infant shows the importance of diaphragmatic breathing in infancy and in this respect it was thought that the vertical displacement of the bifurcation might be relatively greater in infants. As a preliminary investigation it was decided to measure the extensibility of the trachea in infancy and to make comparisons with the adult.

\section{METHOD}

Specimens were taken at necropsy. The larynx, trachea, and the roots of the primary bronchi were dissected free from the surrounding tissues as they lay in situ and then removed en bloc, taking care not to stretch the specimen. The arch of the cricoid was carefully cleaned and defined. A fine pin was then pushed through the point of bifurcation so that the carina was transfixed. A measurement was then made between the lower border of the cricoid arch and the pin. The trachea was extended by gradually increased weights applied to the carina.

It was found that increased loading of the trachea produced a gradually decreasing amount of extension until a stage was reached at which further loading produced much less extension, and this was taken as the point of full extension. It was found to occur when a weight of approximately $20 \mathrm{~g}$, was applied to an infant trachea, or about $80 \mathrm{~g}$. to that of an 
adult in middle life, and about $140 \mathrm{~g}$. to that of a senile adult. The increase in length was expressed as a percentage of the initial measurement.

Specimens were examined from 31 adults and 20 newborn infants, together with specimens from two children and two adolescents. The ages ranged from birth to 88 years. Of the infants, some were stillborn and others had survived for periods from 15 minutes to three days. Eight infants were premature. Specimens were selected from cases without overt pulmonary disease.

\section{RESULTS}

The findings in mature infants and adults are shown in Fig. 1. In the full-term infant the trachea may be extended, on the average, by $46 \%$ of its original length (range 32.5-64.5) and this may be compared with the extensibility of 15 to $20 \%$ in the aged. There is a significant inverse relationship between age and extensibility (coefficient of relation, $\mathrm{P}=<0.001$ ). It was felt that post-mortem changes might influence the extensibility. The coefficient of relation between extensibility and time elapsing between death and examination was calculated $(P=>0.10)$. It would therefore appear that there is no relationship between the amount of extensibility and the time elapsing between death and examination of the material, under the conditions of these experiments (the maximum time elapsing was 63 hours and the minimum three hours, with a mean of 38 hours).

Thus, the trachea may be extended further in infancy than in later adult life. A regression line (Fig. 1) was calculated for the data from the specimens from subjects of the age group 16 to 85 years. There appears to be a linear relationship between age and extensibility of the trachea

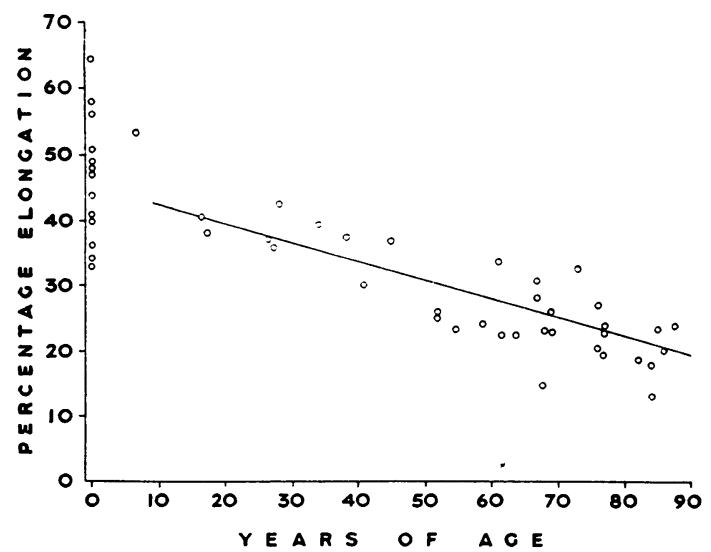

FIG. 1.-The maximum extensibility, expressed as percentage elongation under maximal tension, of the trachea in relation to age. from about 15 years of age onwards. Over each decade the extensibility decreases by $3 \%$. More data would be desirable between the period of birth to 15 years before the relationship at this period is established, but preliminary observations suggest little change in extensibility over this period.

\section{Discussion}

What is the significance of the great extensibility of the trachea at birth and in infancy and the gradual decline in the extensibility of the trachea from the age of 15 years onwards ? This might be due to gradually increasing senile changes in the elastic tissue in the trachea (Figs. 2, 3, 4) occurring pari passu with changes in elastic tissue throughout the body as a whole. Lansing, Roberts, Ramasarma, Rosenthal, and Alex (1951) described changes in the chemistry of arterial elastic tissue with age. There was an increase in the dicarboxylic amino-acid content with increasing age and this was associated with an increased affinity for calcium by aortic elastin, the increase beginning between the ages of 15 and 25 years. It may be, therefore, that the greater tracheal extensibility is merely an expression of the juvenile state of elastic tissue in infancy in the body as a whole and that it does not have any specific functional significance. However, Lansing and others (1951) also examined pulmonary arterial elastin from subjects in the age range 15-92 years and no significant changes were found in the amino-acid composition. Generalizations upon the properties of elastin in various tissues at various ages must therefore be guarded.

If, however, there is a special functional significance of the greater extensibility of the trachea in infancy, in what mechanisms may it be concerned? There are three in which it may play a part. First, it may be related to the mechanism of lung expansion in the infant. Secondly, it may be related to the mechanical expression of mucus from the abundant mucous glands in the submucosa of the infant trachea. Thirdly, it may be associated with a free range of movement of the head and neck (Testut and Latarjet, 1949). However, as the neck of an infant is comparatively short this does not explain the greater extensibility during infancy. Also, according to Mehnert (1901) the bifurcation of the trachea lies at a higher level in infants and is at the level of the third thoracic vertebral body.

Relationship to LUNG EXPansion IN THE INFANT.-The more horizontal position of the ribs in infants implies a lesser role of the thoracic 
movement in respiration, compared with that of the diaphragm. Dally (1908) described the relatively greater proportion of the diaphragmatic surface of the lung to that of the remaining pleural surfaces of the lung in the infant compared with the adult. Thus, if the total pleural surface of the lung is represented as 100 units, then in the infant the diaphragmatic surface constitutes about $25 \%$ of the total. By the age of 35 years this has fallen to about $15 \%$. If diaphragmatic movement is more important in infants than in adults, then lung expansion is mainly in a supero-inferior direction and the vertical movement of the carina would be greater. Increased extensibility of the trachea would obviously facilitate this movement. But inspiratory descent of the carina could result from either of two mechanisms or a combination of these, viz., actual elongation of the trachea and inferior displacement of the trachea as a whole, which in its turn requires inferior displacement of the larynx.

Respiratory displacement of the larynx has been studied by a number of workers. Weingaertner (1920) investigated changes in the level of the larynx and of the carina, also changes in the length of the trachea with respiratory movements in 20 subjects, aged 16 to 56 years. He found that in ordinary respiration there was an inspiratory depression of the larynx by 1 to 10 $\mathrm{mm}$. in eight cases, whereas in three there was an inspiratory elevation by 1 to $5 \mathrm{~mm}$. In 11 cases he measured respiratory changes in the

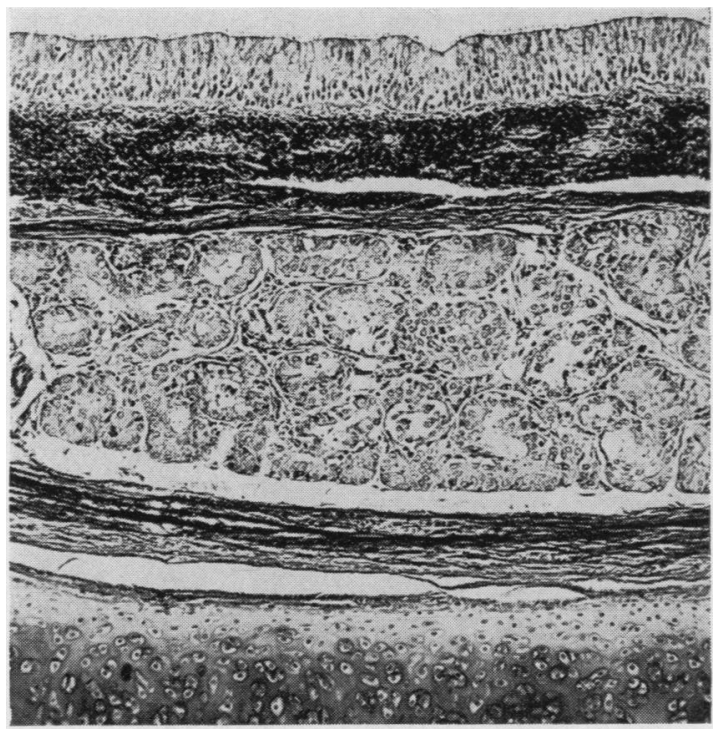

Fio. 2

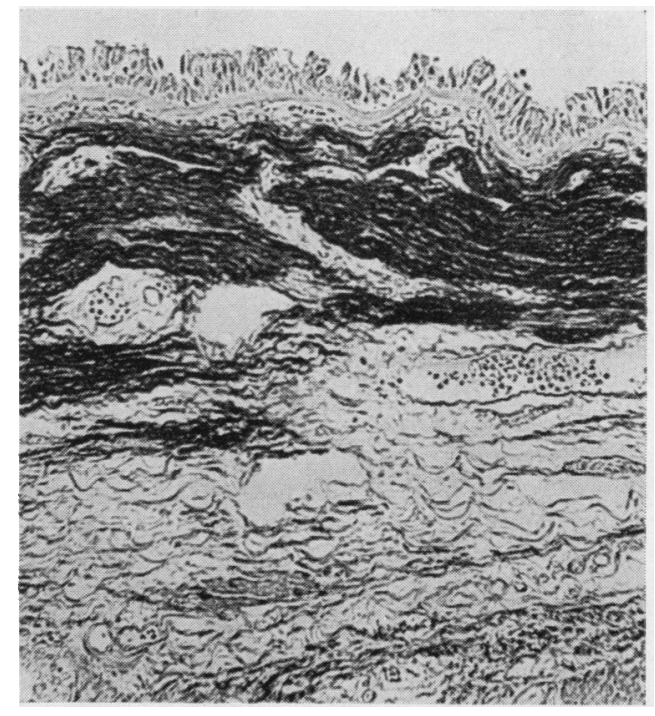

Fig. 3

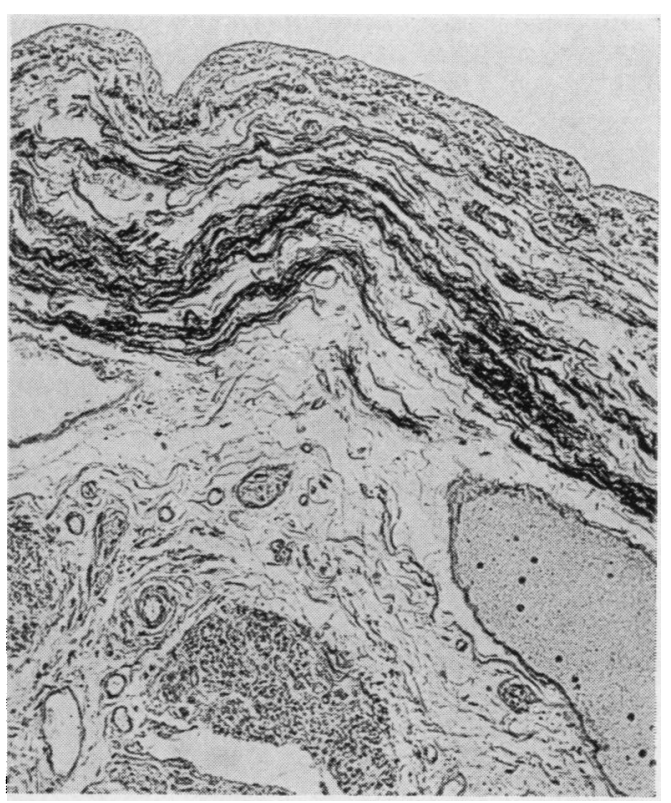

Fig. 4

Fig. 2.-Transverse section of trachea, infant aged 5 months, showing internal elastic lamina. Orcein, haematoxylin, acid fuchsin. $\times 60$.

FIG. 3.-Longitudinal section of trachea, adult aged 46 years, showing internal elastic lamina. Orcein, haematoxylin, acid fuchsin. $\times 60$.

Fig. 4.-Longitudinal section of trachea, adult aged 85 years, showing internal elastic lamina. Orcein, haematoxylin, acid fuchsin. $\times 60$. 
length of the larynx: in five cases there was inspiratory lengthening by 2 to $7 \mathrm{~mm}$., in three cases no change, and in three an expiratory elongation by 1 to $3 \mathrm{~mm}$. Measurements were made by endoscopic techniques in anaesthetized subjects with the head extended. The inhibitory effect of head extension upon movement at the carina has been noted elsewhere (Harris, 1959). Mitchinson and Yoffey (1947) examined 23 normal subjects aged 15 to 45 years, and radiographs were taken at the extremes of inspiration and expiration. In five cases there was slight inspiratory elevation, in four cases slight inspiratory descent (the amount of movement, whether elevation or depression, did not exceed $\frac{1}{4}$ in. $(6 \mathrm{~mm}$.) in any of the cases), and in the remaining 14 cases no respiratory displacement occurred. Brückner (1952), using the position of the vocal folds as an index of the laryngeal position, noted a definite elevation with expiration, the change in level being, on the average, the height of one cervical vertebral body and in some cases even of two vertebrae. Holden and Ardran (1957) noted that although there was little movement of the larynx with quiet breathing it moved downwards with inspiration. These authors also noted that on deep inspiration the trachea increased in length up to one-fifth.

Thus, two factors facilitate descent of the carina. First, actual extension of the trachea, accounting for most of the movement, and, secondly, in the terminal part of inspiration, inferior displacement of the trachea and larynx as a whole. Displacement of the trachea as a whole accounts for about $16 \%$ of the total movement of the carina in young adult males (Harris, 1959).

It is interesting to note that in old age the larynx has descended to a lower level (Mehnert, 1901 ; Negus, 1930). The descent of the larynx with advancing age possibly compensates for the diminished extensibility of the trachea and would facilitate the inferior respiratory displacement of the carina.

Role of Tracheal Extension in Promoting LUNG EXPANSION.-Keith (1909) noted that the increase in thoracic capacity due to an inspiratory movement occurs mainly inferiorly due to movement of the diaphragm. Numerous investigations have shown that the bronchi elongate with inspiration. Holden and Ardran (1957) noted that the bronchi elongate by $25 \%$ on deep inspiration. Since the apices cannot expand superiorly due to the resistance of the suprapleural membrane and scalene muscles and but little antero-posteriorly, any elongation of the bronchi in the upper lobes must be mainly in an inferior direction, i.e., by a downward movement of their points of origin (Macklin, 1929) which move with the lung root. Macklin (1925) examined bronchograms for evidence of greater elongation of the upper than the lower lobe bronchi, but, due to technical limitations, the bronchial outlines at expiration could not be compared with those at inspiration. Tracheal extension would thus facilitate the vertical elongation of the bronchi above the level of the lung root.

\section{Effect of Head Posture upon Air Flow IN RESPIRATION}

To investigate the importance of the inferior inspiratory displacement of the carina in pulmonary ventilation, the forced inspiratory volume in normal subjects was compared with the head in the flexed and then in the fully extended position (the terminology used in this section is that recommended by Gandevia and Hugh-Jones, 1957). With full head extension the larynx might be held more fixed by the various attachments of the thyroid cartilage to the hyoid bone, which, in its turn, is attached to the base of the skull (Mitchinson and Yoffey, 1947). Also, with head extension, the trachea is extended from its upper end (Harris, 1959) and consequently inspiratory descent of the carina is impaired (v.i.).

Recordings were made using a vital-capacity spirometer with a very light-weight spirometer bell. The bell was connected to a wide-bore metal mouthpiece $(4.5 \mathrm{~cm}$. internal diameter) by a rubber connexion of the same internal diameter to minimize resistance to air flow. Its movements were recorded on an electrically driven kymograph moving at $1.7 \mathrm{~cm}$. $/ \mathrm{sec}$. The drum speed was checked by an electric time-marker.

Care was taken that the position of the subject was constant during each examination and that the only variation in this respect was that of the subject's head. Peltier and Visscher (1952) emphasized the effect upon tidal volume of resistance to air flow in the upper respiratory passages by comparing nasal and mouth breathing. Tidal volumes were greater when breathing with the mouth widely open. Accordingly, to eliminate the variability of nasal breathing and to ensure minimal buccal resistance to air flow, the nose was clipped and a large-aperture mouthpiece used. The head was supported in the extended position.

With the subject sitting upright, two successive pairs of inspiratory movements were recorded 
(with a rest period between each pair) with the head in flexion and then two pairs with the head in full extension. Thus the mean values for the forced inspiratory volume and the forced ventilatory capacity (inspiratory) both in flexion and extension are based upon the mean of four measurements made upon each of 15 individuals.

The values obtained in 15 healthy young adults ( 2 female and 13 male, average age 32 years) for the forced inspiratory volumes (F.I.V.) during each 0.25 second of the first second of inspiratory movements with the head in flexion and then in full extension were as follows:

During the first $0.25 \mathrm{sec}$ (F.I.V. $\cdot_{0.25}$ ) the mean flow in flexion was $1,510 \mathrm{ml}$. (S.E. 250), whereas in extension it was $1,160 \mathrm{ml}$. (S.E. 180). Thus the F.I.V. 0.25 in flexion exceeded that in extension by $350 \mathrm{ml}$. During the second 0.25 sec. $($ F.I.V. $\cdot 0 \cdot 25-0.5)$, the mean flow in flexion was $1,450 \mathrm{ml}$. (S.E. 170) and in extension 1,320 ml. (S.E. 120), the rate in flexion thus exceeding that in extension by $130 \mathrm{ml}$. Therefore over the first $0.5 \mathrm{sec}$. of inspiration the air flow with the head in the flexed position exceeded by almost $500 \mathrm{ml}$. that in head and neck extension, the difference being highly significant statistically $(P=<0.001)$. However, in the second $0.5 \mathrm{sec}$. of the inspiratory movement there was no significant difference between the two sets of data $(P=>0.05)$. Thus the F.I.V. $\cdot_{0 \cdot 5-0.75}$ in flexion was $770 \mathrm{ml}$. (S.E. 110) whereas in extension it was $840 \mathrm{ml}$. (S.E. 90). The F.I.V..$_{0 \cdot 75-1 \cdot 0}$ in flexion was $370 \mathrm{ml}$. (S.E. 80) and in extension was $430 \mathrm{ml}$. (S.E. 90). The forced vital capacity (inspiratory) in the position of flexion was 4,340 $\mathrm{ml}$. and in that of extension was $4,010 \mathrm{ml}$.

In 13 of the 15 subjects there was a consistently greater flow of air throughout the whole of the first second of the inspiratory movement in head flexion compared with head extension. Thus the amount by which the F.I.V. in flexion exceeded that in extension, during the first second of inspiratory movements, was as follows: F.I.V..$_{0.25}$, $350 \mathrm{ml}$. (S.E. 130) ; F.I.V.$_{0.5}$, $480 \mathrm{ml}$. (S.E. 120);

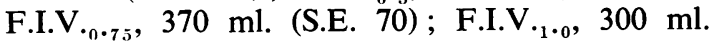
(S.E. 70).

If the forced inspiratory volumes during each quarter of the first second of inspiratory movements are expressed as a percentage of the maximum forced vital capacity achieved, then the flow rates in the second half of the inspiratory movement are practically the same when the head is in either the flexed or the extended position $(30.4 \%$ and $31.9 \%$ respectively of the forced vital capacity). But during the first half

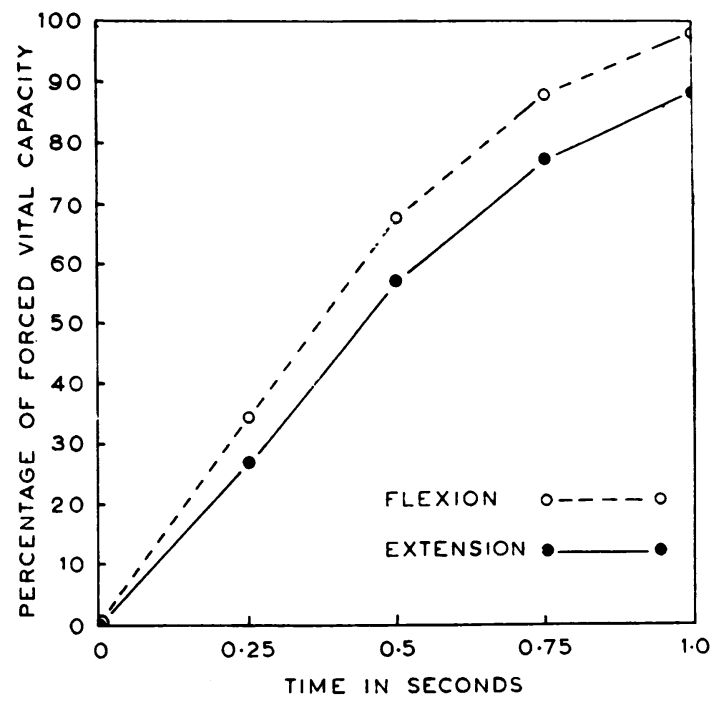

FIG. 5.-Percentage of forced vital capacity achieved during first second of inspiratory movements in head flexion and extension. (Mean values from 15 adults.)

of the movement the value in flexion exceeds that in extension by about $10 \%$, i.e., $67.4 \%$ compared with $56.9 \%$. By the end of the first second of inspiration, $97.8 \%$ of the air flow has taken place when the head is flexed, but only $88.8 \%$ when the head is extended. Thus inspiration is prolonged in head extension (Fig. 5).

EFFECT OF HEAD EXTENSION UPON FORCED INSPIRATORY VOLUMES.- Head extension produces extension of the trachea and infrahyoid respiratory passage (Harris, 1959) which may interfere with lung expansion in three ways:

(1) Mechanical Limitation of Inferior Displacement of the Carina.-Head extension stretches the trachea by an amount equal to its inferior inspiratory displacement, about $2.5 \mathrm{~cm}$. (Harris, 1959), and this would leave less extensibility available for inferior respiratory displacement of the carina. If the lung root does not descend then expansion of the apical regions of the lung might be limited.

(2) "Sensitization" of Stretch Reflexes.-Sensory nerve endings, termed "smooth muscle nerve spindles," have been described in the smooth muscle of the human trachea (Jabonero, 1952). Similar nerve spindles, sensitive to mechanical stimuli, have been described in the human main bronchi (Larsell and Dow, 1933 ; Gaylor, 1934). Larsell and Dow also noted sensory fibres in the perichondrium on the inner surfaces of cartilages in the main bronchi and considered these were 


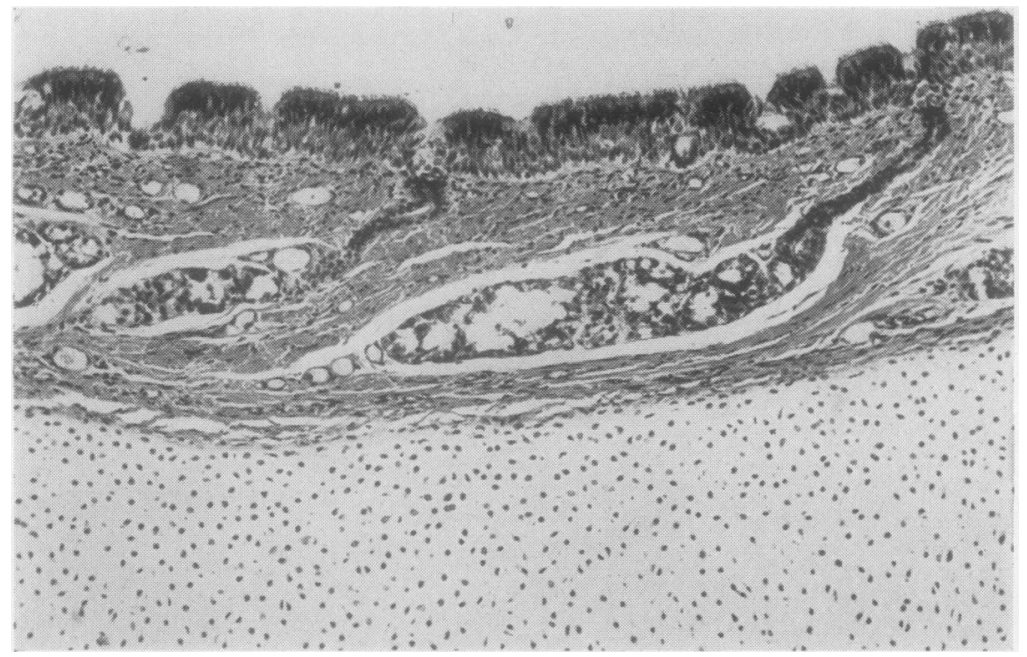

Fig. 6.-Transverse section of trachea, full-term infant, showing ducts leading from acini to surface of mucous membrane. Haematoxylin, Masson red, and light green. $\times 60$.

stimulated mechanically. Further experiments presented in this paper (v.i.) show that tracheal extension produces deformation of the cartilages and perichondria. This supports the concept of mechanical stimulation of the perichondrial nerve endings with tracheal extension. Tracheal extension and consequent stimulation of the mechanoreceptors could produce reflex respiratory slowing and bronchoconstriction (Widdicombe, 1954). In a trachea already stretched by head extension, further extension by inspiratory descent of the lung root will accentuate stimulation of these receptors so that the inhibitory respiratory effect of the reflexes which they mediate would occur earlier in the course of the inspiratory movements.

(3) Narrowing of the Tracheal Lumen.-Head extension causes a significant narrowing of the tracheal lumen (Harris, 1959) and consequently an increase in resistance to air flow.

Extension of the head and neck might interfere with the function of the muscles acting upon the thoracic inlet (scaleni and sternomastoids) and this could occur in two ways: first, by a change in the resting length of the muscle fibres and, secondly, by a change in their angle of insertion. To investigate the first of these two factors the distance between the transverse processes of the first and fourth cervical vertebrae and the medial end of the clavicle (taken as an index of the medial end of the first rib) was measured on radiographs used in a study of head and neck extension upon the trachea (Harris, 1959). On the average, the resting length of the upper fibres of the scaleni was increased by $4.3 \%$ with head extension and that of the lower fibres by $7.2 \%$. Hill (1925) investigated the tension developed in muscle whose resting length was varied. With a $5 \%$ increase in resting length, the tension developed was about $90 \%$ of the maximum attainable. Thus head extension, by slightly stretching the scalene muscles, may slightly diminish their potential activity. The effect of this upon a forced inspiratory movement is difficult to predict.

\section{Clinical Significance of Tracheal Extension}

The retrosternal pain associated with acute tracheitis and bronchitis is accentuated by deep inspiration. Under these circumstances reflex restriction of the descent of the lung root by painful stimuli might be produced by extension of the inflamed trachea and bronchi. If this were associated with concomitant diseases, e.g., nutritional anaemia and congestive cardiac failure, then the restriction of pulmonary ventilation might become significant.

Disease of the tracheo-bronchial lymph nodes could restrict lung root movement in two ways. First, inflammatory disease of these nodes may cause infiammation of the adjacent mediastinal pleura which then, if pulled upon by forces transmitted from the inferior displacement of the carina, causes pain and consequent reflex inhibition of inspiration. Secondly, the lung root may become fixed mechanically. The evidence upon this question is equivocal. Wilson, Edwards, and Liss (1924) studied children with tracheo-bronchial adenopathy and concluded that a significant reduction in vital capacity occurred with latent or healed infection and was even greater in active infection. The decrease in vital capacity was explained by loss of lung elasticity, but pathological investigations were not made and they did 
FIG. 7.-Transverse section of trachea, infant aged 5 months, showing abundant mucous glands. Orcein, haematoxylin, acid fuchsin. $\times 60$.

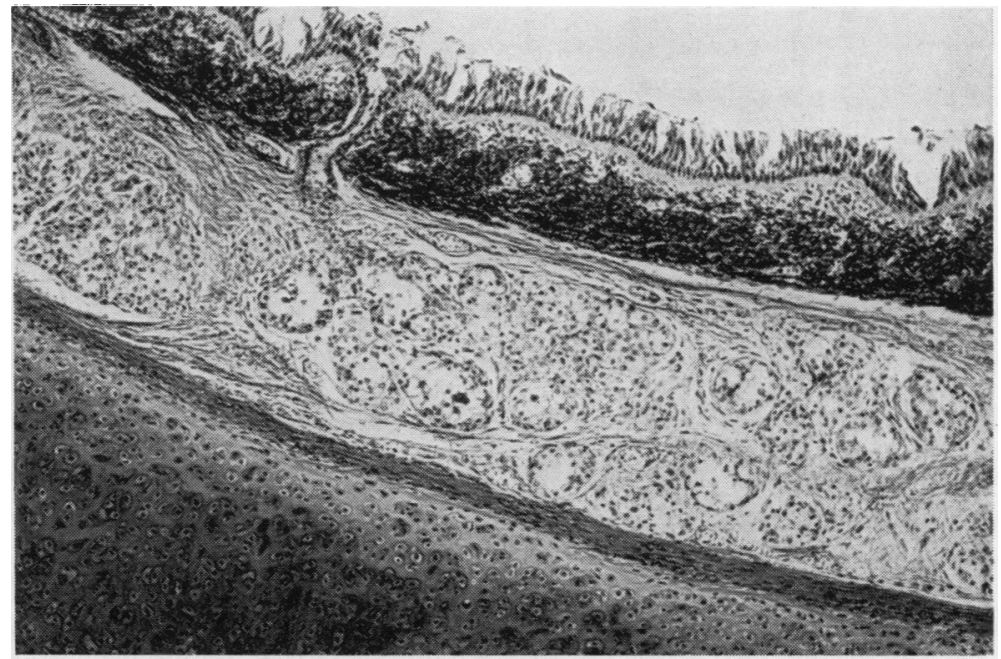

not consider such factors as pulmonary vascular engorgement associated with active infection or mechanical obstruction of pulmonary vessels by enlarged nodes. Friedman and Hawes (1929) investigated children with clinical and radiographic signs of enlarged tracheo-bronchial nodes and did not find any significant decrease in vital capacity.

\section{Mechanism of Secretion of Tracheal Mucus}

Two groups of cells in the human trachea produce mucus: goblet cells in the surface epithelium, and tubulo-acinar glands in the submucosa, lying external to the internal elastic lamina. The secretion reaches the surface of the mucous membrane through the tubular ducts leading through gaps in the elastic lamina (Fig. 6). In addition, there are numerous serous glands, situated with the mucous glands, whose secretion obviously varies the viscosity of the ultimate secretion. Glands are particularly abundant in the submucosa of the newborn infant (Fig. 7).

Florey, Carleton, and Wells (1932), considering the mechanism of tracheal mucus secretion, noted that vagal stimulation excites copious secretion from the glands in the submucosa, but that in the heavily atropinized cat the deep glands still secrete mucus and that some other, possibly reflex, mechanism may be concerned. Secretion of mucus from the stomach can be provoked by mechanical stimuli alone. Thus, some factor or factors, other than direct neural control, may also be concerned in tracheal mucus secretion. The tracheal muscle and elastic tissue might be involved.
What part may the tracheal muscle play in the secretion of mucus? Borelli (1949) found that certain of the transverse muscle fibres, lying deeper than those attached to the cartilages, were attached to the submucosa and internal membrane of the trachea, and on contraction could transversely shorten the pars membranacea, raising the mucous membrane into longitudinal folds. This, he considered, might have a squeezing action upon the glandular elements. But the glandular elements lie superficial to the muscle (Stirling, 1883 ; Miller, 1913) and there would seem little evidence, structurally, that the tracheal muscle directly promotes mucus secretion by mechanical compression of the glandular acini.

Role of Tracheal Elastic Tissue.-Grossly the elastic tissue is arranged in two main strata: a thicker stratum (the internal elastic lamina) lying beneath the mucous membrane and a less prominent stratum (the external elastic lamina) lying superficial to the tracheal cartilages. The two strata are connected together between the cartilaginous rings. Examination of longitudinal sections reveals a typical pattern in the fibres passing between the cartilaginous rings and linking the inner and outer elastic laminae (Fig. 8). The lobules of the glands are surrounded by elastic and collagenous fibres and fibrous septa which subdivide them into acini (Fig. 9). WolfHeidegger (1947) described a lattice arrangement of the fibres in the elastic laminae, the constituent fibres being oblique and crossing each other to form a meshwork. Those angles of the meshwork directed superiorly and inferiorly vary with the longitudinal stretching of the trachea, becoming 


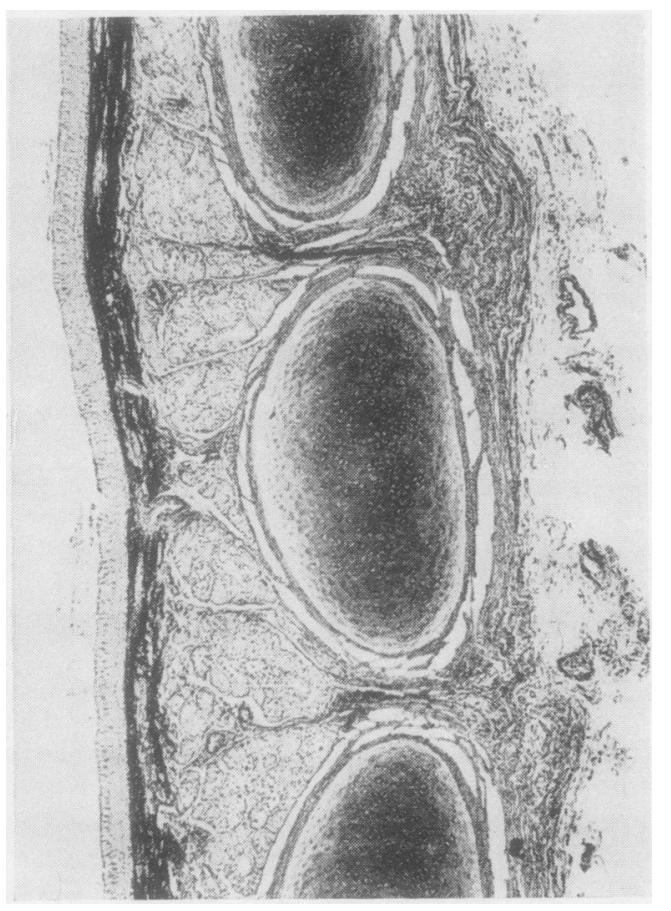

FIG. 8.-Longitudinal section of trachea, full-term infant, showing fibres passing between the cartilaginous rings and connecting the inner and outer elastic laminae. Orcein, haematoxylin, and Van Gieson. 23.

more acute with tracheal extension. One meshwork lies in a frontal plane and the other in a sagittal plane. Longitudinal sections show the crossing of the oblique fibres in the sagittal plane. This histological pattern may be of functional significance, extension of the trachea tending to cause compression of the mucous glands lying between the fasciculi of the stretched lattice. Wolf-Heidegger (1947) considered that the chief function of the lattice was to facilitate tracheal extension, the arrangement of the connective tissue in relation to the glandular acini being part of the general lattice pattern. However, he also noted that it might be concerned with the mechanism of mucus secretion.

To investigate this hypothesis, longitudinal sections of the fibro-cartilaginous ventral tracheal wall from newborn infants were examined histologically. A small longitudinal strip was taken and divided longitudinally into two parts. One strip was fixed (formol saline) in the extended state and the other in the unextended state. Thus, the form of the acini in the submucosa was compared in the extended and unextended specimens. Tracheal extension produced definite glandular compression (Figs. 10-13), especially of those glands subjacent to the inner surfaces of the cartilages (Figs. 12 and 13). Tracheal extension also caused deformation of the cartilages and surrounding perichondria (Figs. 12 and 13), possibly an important factor in the of stimulation of sensory endings in the perichondrium (v.s.).

Assuming a functional relationship between $\vec{\omega}$ the submucosal glands and the fibrous lattice in $\vec{F}$ which they fie, then with deeper or more frequent respiration (and, a priori, tracheal extension) there $\overrightarrow{\vec{A}}$ might be a greater secretion of mucus by $\omega$ mechanical expression of material from the $\stackrel{N}{\mathcal{O}}$ ducts and acini. This point is being investigated further.

\section{Summary and Conclusions}

The importance of tracheal extension in $\frac{\mathbb{D}}{8}$ respiration was investigated by extending the $\stackrel{\mathbb{D}}{7}$ trachea from its upper end by head and neck $\frac{}{0}$ extension. This reduces the extensibility avail- $\mathbb{D}$ able for the inferior inspiratory displacement of the carina.

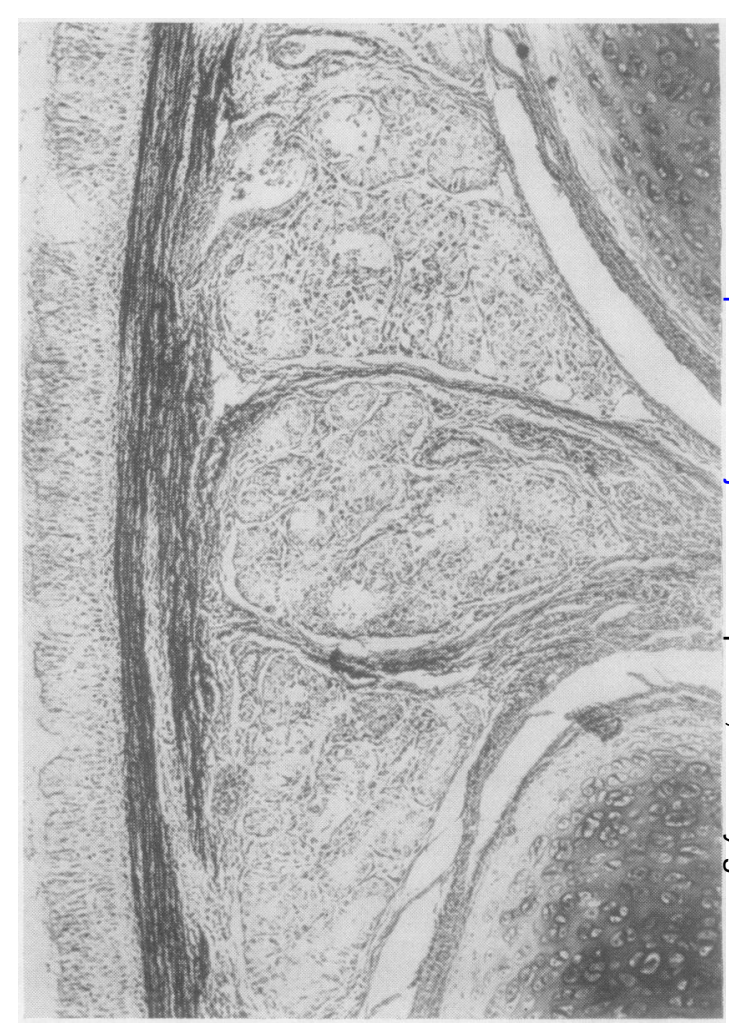

FIG. 9.-Longitudinal section of trachea, infant aged 5 months, $\overparen{\mathbb{D}}$ showing septa dividing lobules of glands. Orcein, haematoxylin, acid fuchsin. $\times 60$. 


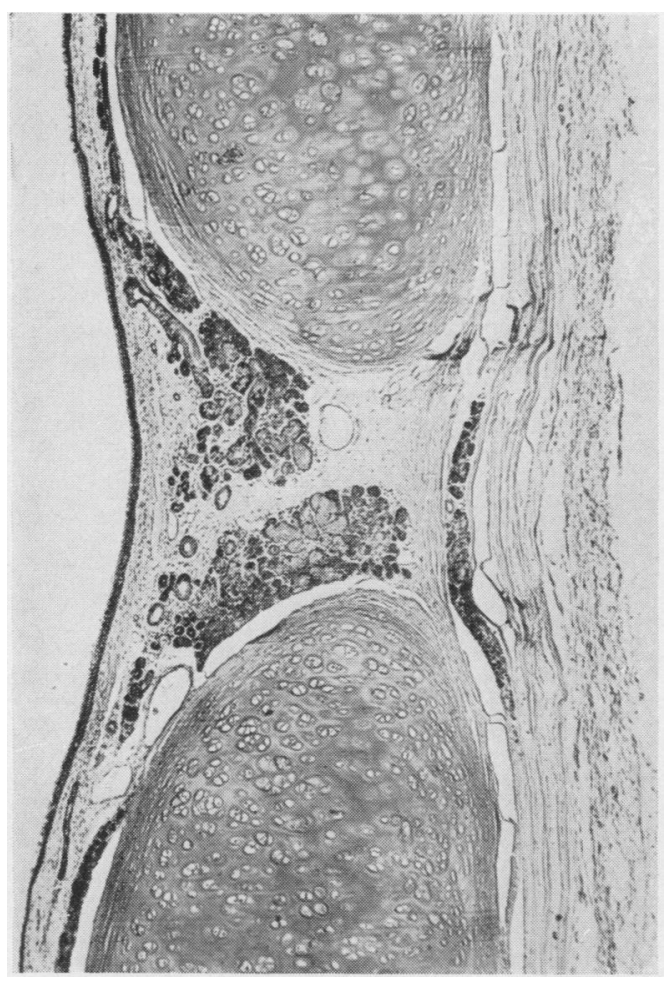

Fio. 10

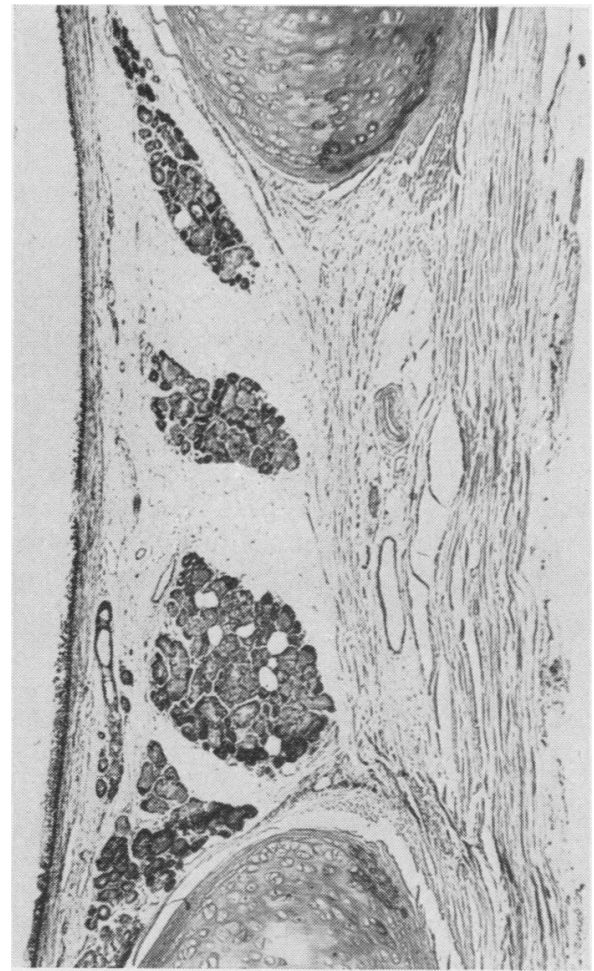

FIo. 11

Fig. 10.-Longitudinal section of trachea, adult aged 55 years, fixed in unextended position. Note the general situation of the acini. Mucicarmine. $\times 23$.

Fig. 11.-Longitudinal section of trachea, adult aged 55 years, fixed in extended position, cf. Fig. 10. Mucicarmine. $\times 23$.

Fig. 12.-Longitudinal section of trachea, mature infant, fixed in unextended state. Orcein haemalum. $\times 23$.

Fig. 13.-Longitudinal section of trachea, mature infant, fixed in extension. cf. Fig. 12 Orcein, haemalum, Alcian blue. $\times 23$

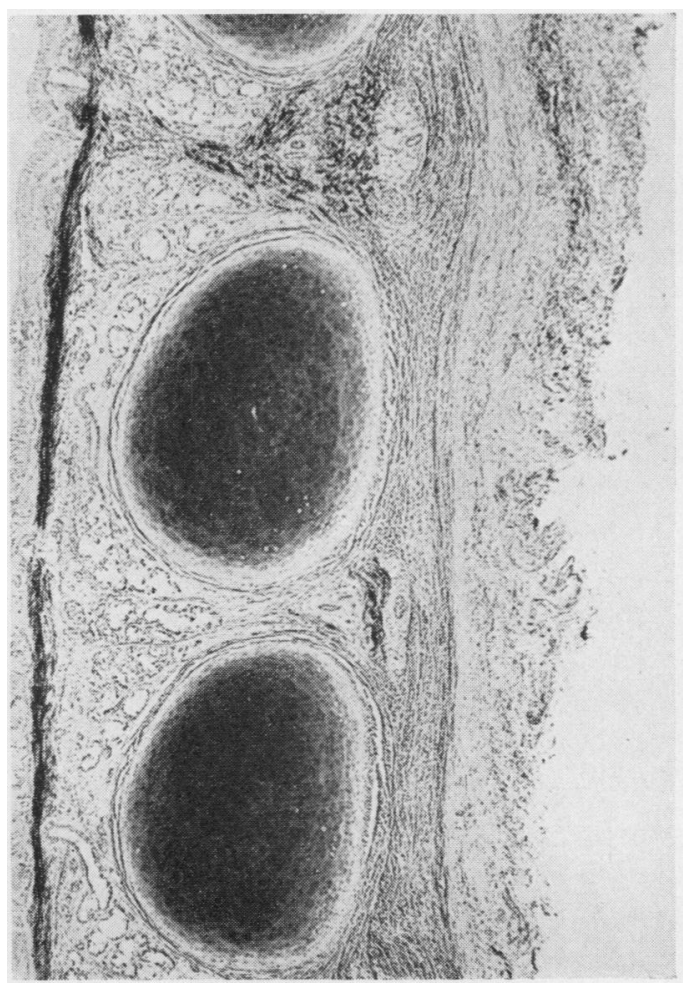

Fig. 12

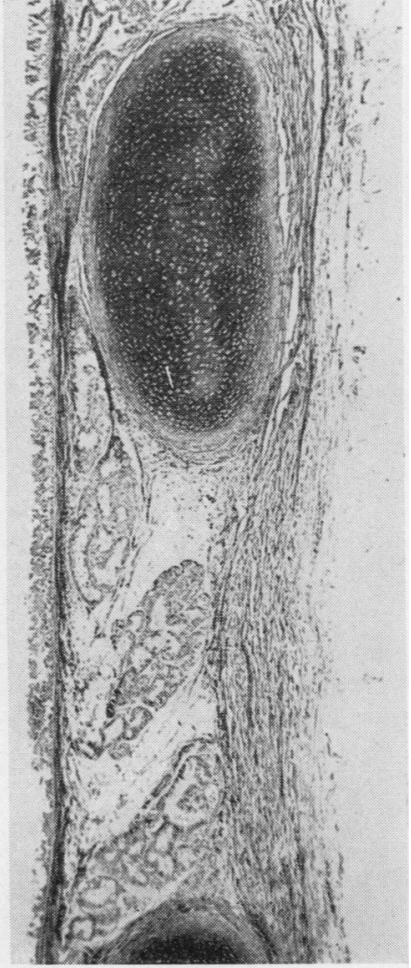

FIG. 13 
Head extension in healthy young adults caused a diminution of the forced inspiratory volume by $500 \mathrm{ml}$. over the first half second of forced inspiration and also prolonged the inspiratory phase in forced breathing.

The flow rate in the first half second of forced inspiratory movements was about $10 \%$ less when the head and neck were fully extended than when the head was flexed, but there was no significant difference in the second half second. The diminished flow rate in head and neck extension may be due to two factors: first, a significant narrowing of the antero-posterior diameter of the supraclavicular portion of the trachea, due to the anterior displacement of the membranous portion of the tracheal wall; and, secondly, stimulation of stretch receptors in the smooth muscle of the trachea and of sensory endings in the perichondria. Free tracheal extension is important in the mechanism of respiration, facilitating the inspiratory descent of the lung root.

The extensibility of the human trachea was examined over the age range of birth to 88 years. There is a marked decrease in extensibility with age. At birth, the trachea can be extended, in vitro, by about $46 \%$ of its unextended length. At about 15 years of age the extensibility begins to diminish by about $3 \%$ every 10 years and declines to about 15 to $20 \%$ in old age. The greater extensibility in infants and children is probably associated with a predominantly diaphragmatic respiration.

Extension of the trachea causes compression of the acini of the mucous glands, especially those lying between the cartilages and the mucous membrane. This may be associated with the mechanical secretion of mucus already present in the ducts and acini. Tracheal extension alse causes deformation of the cartilages and theisperichondria. The latter may give rise to nerve reflexes arising from respiratory extension of th 8 trachea.

I would like to thank Professor J. M. Yoffey and also Professor A. V. Neale for their interest and encouragement. I am most grateful to Dr. N. $\sqrt{\omega}$ Brown, consultant pathologist to Southmead Generas Hospital, and to the pathologists, the Bristol Royal Infirmary, for facilities at necropsies, also to Dr. $\mathrm{H}$ de V. Heese for advice and allowing me the use of the spirometer.

\section{REFERENCES}

Borelli, C. (1949). Atti Soc. med.-chir. Padova, 27, No. 1, p. 122. 음 Brückner, H. (1952), Z. Anat. Entwickl. Gesch., 116, 276.

Dally, J. F. H. (1908). J. Anat. Physiol. (Lond.), 43 [3rd series, 4], 93Engel, S. (1947). The Child's Lung, p. 163. Edward Arnolds London.
. The Child's Lung, p. 163. Edward Arnold

Florey, H., Carleton, H. M., and Wells, A. Q. (1932). Brit. J. exp
Path., 13, 269.

Friedman, E., and Hawes, J. B. (1929). J. Amer. med. Ass., 92, 363 Gandevia, B., and Hugh-Jones, P. (1957). Thorax, 12, 290.

Gaylor, J. B. (1934). Brain, 57, 143

Harris, R. S. (1959). Thorax, 14, 176

Hill, A. V. (1925). J. Physiol. (Lond.), 60, 237.

Holden, W. S., and Ardran, G. M. (1957). J. Fac. Radiol., 8, 267. G Jabonero, V. (1952). Pract. oto-rhino-laryng. (Basel), 14, 38 Keith, A. (1909). In Further Advances in Physiology, p. 182. Ed. by Leonard Hill. Edward Arnold, London.

Lansing, A. I., Roberts, E., Ramasarma, G. B., Rosenthal, T. B., an Alex, M. (1951). Proc. Soc. exp. Biol. (N.Y.), 76, 714.

Larsell, O., and Dow, R. S. (1933). Amer. J. Anat., 52, 125.

Macklin, C. C. (1925). R. Ibid., 35, 303 .

Macklin, C. C. (1925). Ibid., 35, 303 .
Mehnert, E. (1901). Uber Topographische Altersveränderungen dề Atmungsapparates. Fischer, Jena.

Miller, W. S. (1913). Anat. Rec., 7, 373.

Mitchinson, A. G., and Yoffey, J. M. (1947). J. Anat. (Lond.), 8

118.

Meltier, L. F., and Visscher, M. B. (1952). J. appl. Physiol., 4, 901. Stirling, W. (1883). J. Anat Physiol. (Lond.), 17, 204.

Testut, L., and Latarjet, A. (1949). Traité d'Anatomie Humaine 9th ed., Vol. 3, p. 945 . Doin, Paris.

Weingaertner, M. (1920). Arch. Laryng. Rhin. (Berl.), 32, 1 ,

Widdicombe, J. G. (1954). J. Physiol. (Lond.), 123, 71.

Wilson M. G. Edwards, D. J., and Liss, I. E. (1924). Amer. Dis. Child., 27, 49.

Wolf-Heidegger, G. (1947). Acta anat. (Basel), 4, 295. 